\title{
Association of ADAMTS-7 Levels with Cardiac Function in a Rat Model of Acute Myocardial Infarction
}

\author{
Wenjing Wu ${ }^{a}$ Hui Wang ${ }^{b}$ Changan Yua Jiahui Lia Yanxiang Gao ${ }^{a}$ Yuannan Ke \\ Yong Wang ${ }^{\text {a }}$ Yifeng Zhou $^{\text {a Jingang Zheng }}{ }^{\text {a }}$ \\ aDepartment of Cardiology, China-Japan Friendship Hospital, Beijing, bepartment of Intensive Care \\ Unit, China-Japan Friendship Hospital, Beijing, China
}

\section{Key Words}

ADAMTS-7 - Acute myocardial infarction - Cardiac function - Cartilage oligomeric matrix protein

\begin{abstract}
Background/Aims: High ADAMTS-7 levels are associated with acute myocardial infarction (AMI), although its involvement in ventricular remodeling is unclear. In this study, we investigated the association between ADAMTS-7 expression and cardiac function in a rat AMI model. Methods: Sprague-Dawley rats were randomized into AMI $(n=40)$ and sham $(n=20)$ groups. The left anterior descending artery was sutured to model AMI. Before surgery and 7 , 14,28 , and 42 days post-surgery, ADAMTS-7 and brain natriuretic peptide (BNP), and cartilage oligomeric matrix protein (COMP) were assessed by ELISA, western blot, real-time RT-PCR, and/or immunohistochemistry. Cardiac functional and structural parameters were assessed by M-mode echocardiography. Results: After AMI, plasma ADAMTS-7 levels increased, peaking on day 28 (AMI: $13.2 \pm 6.3$ vs. sham: $3.4 \pm 1.3 \mathrm{ng} / \mathrm{ml}, P<0.05$ ). Compared with the sham group, ADAMTS-7 expression was higher in the infarct zone at day 28. COMP present in normal myocardium was degraded by day 28 post-AMI. Plasma ADAMTS-7 correlated positively with BNP $(r=0.642, P=0.025)$, left ventricular end-diastolic diameter $(r=0.695, P=0.041)$, left ventricular end-systolic diameter $(r=0.710, P=0.039)$, left ventricular ejection fraction $(r=$ $0.695, P=0.036)$, and left ventricular short-axis fractional shortening $(r=0.721, P=0.024)$. Conclusions: ADAMTS-7 levels may reflect the degree of ventricular remodeling after AMI.
\end{abstract}

\section{Introduction}

Acute myocardial infarction (AMI) encompasses a spectrum of conditions leading to myocardial ischemia and/or necrosis secondary to a reduction in coronary blood flow [1].

W. Wu and $\mathrm{H}$. Wang contributed equally to this study. 
Adults with coronary disease may suffer from AMI, especially men [1]. Incidence of AMI was 208 per 100,000 person-years in 2008 in the United States [2]. In-hospital mortality is about $4.6 \%$, and 6-month mortality is about 4.5\% [3]. Survivors suffer from a variety of conditions including heart failure, pulmonary edema, recurrent myocardial infarction, and stroke [3]. Current treatments are efficient since mortality steadily decreased from 1995 to 2010 [4], but some patients still die from AMI since the mortality rate was 4.4\% in 2010 [4]. Therefore, studying the exact pathological mechanisms involved in AMI is crucial to develop new strategies.

Ventricular remodeling plays an essential role in the development of AMI, and the extracellular matrix (ECM) plays a major role in the maintenance of ventricular shape, size, and function [5]. ECM degradation requires the activation of extracellular proteases, which in turn participates in ventricular remodeling [6]. Many studies have proved that matrix metalloproteinases (MMP) play important roles in matrix degradation and ventricular remodeling [7, 8]. However, clinical trials revealed that broad-spectrum MMP inhibitors are associated with severe side, indicating that more comprehensive knowledge about proteases is needed [9].

Unlike MMPs, A Disintegrin And Metalloproteinase with Thrombospondin Motifs (ADAMTS) demonstrate a narrow substrate specificity to cartilage oligomeric matrix protein (COMP) due to the various exosites located in the C-terminal region of the enzyme, which influence protein recognition and matrix location [10]. This narrow specificity suggests that ADAMTS could be potentially safe pharmaceutical targets [11]. ADAMTS-7 expression was detected as a 5-kb transcript in adult human samples, with heart, pancreas, kidney, skeletal muscle, and liver having the highest levels of expression [11]. A previous study by our group showed an association between plasma ADAMTS-7 levels and left ventricle (LV) function after AMI [12]. However, the exact involvement of ADAMTS-7 in ventricular remodeling still needs to be determined.

The aim of the present study was to examine the association between ADAMTS-7 expression and cardiac function in rats with AMI. Results showed that COMP were degraded 28 days after AMI, and that ADAMTS-7 levels correlated with cardiac function. These suggest that ADAMTS-7 participates in myocardial remodeling after AMI and that it could be a treatment target.

\section{Materials and Methods}

\section{Animals}

Male Sprague-Dawley rats $(n=60$, aged 8 weeks, weighing $240 \pm 20 \mathrm{~g}$ ) were purchased from the Institute of Laboratory Animal Sciences (Beijing, China). They were housed four by cage in a controlled environment ( $23 \pm 1^{\circ} \mathrm{C}, 45-50 \%$ relative humidity; $12 / 12 \mathrm{~h}$ light/dark cycle, lights on at 08:00) with food and water ad libitum. All procedures were performed in accordance with the National Institute of Health's Guide for the Use and Care of Laboratory Animals and were approved by the Committee on animal Care and Use of the China-Japan Friendship Hospital (Beijing, China).

\section{Acute myocardial infarction rat Model}

After a 7-day acclimation, 60 SD rats were randomized into the AMI $(n=40)$ and sham $(n=20)$ groups. AMI models were induced as previously described [13]. Rats were anesthetized with $1 \%$ pentobarbital sodium $(50 \mathrm{mg} / \mathrm{kg}$, intraperitoneal injection). They underwent tracheotomy and a left intercostal thoracotomy at the fourth and fifth intercostal space. The left anterior descending artery (LAD) was secured $2.0 \mathrm{~mm}$ below the level of the tip of the normally positioned left auricle. The LAD was permanently ligated with 8-0 nylon sutures. The sham-operated animals underwent the same procedure except that the silk suture was placed around the left coronary artery without being tied. The occurrence of lethal arrhythmia was 65\% (26/40) 60 min after AMI. Heart massage was performed and successfully saved 42\% (11/26) of the rats with arrhythmia. The chest wall was closed. The rats were returned to their cages and fed routinely for 6 weeks. After surgery, all animals were injected with penicillin for three days to prevent infection.

\section{KARGER}




\section{Cellular Physiology Cell Physiol Biochem 2016;38:950-958 and Biochemistry Published online: March 04, $2016 \quad \begin{aligned} & \text { DOI: 10.1159/000443016 The Author(s). Published by S. Karger AG, Basel } \\ & \text { www.karger.com/cpb }\end{aligned}$ \\ Wu et al.: ADAMTS-7 and Cardiac Function in Rats with AMI}

Data collection

Plasma ADAMTS-7 determined by enzyme-linked immunosorbent assay (ELISA), brain natriuretic protein (BNP) levels, and cardiac functional and structural parameters determined by echocardiography were assessed before operation and at $7,14,28$, and 42 days after operation.

Hearts from the AMI and sham groups ( $\mathrm{n}=21$ and 18, respectively) were excised 28 days after AMI. Parts of the excised hearts were quickly frozen in liquid nitrogen. Remaining parts were embedded in optimal cutting temperature compound (OCT), fixed for immunohistochemistry, and preserved at $-80^{\circ} \mathrm{C}$.

Neurohumoral and biochemical studies

Blood was collected from the cervical vein at 4 weeks in both groups for neurohumoral and biochemical assays. The rats were temporarily anesthetized with a mixture of $1.2 \%$ halothane in oxygen-enriched air for $10 \mathrm{~min}$, and $3 \mathrm{ml}$ of blood was promptly collected. The sample was divided into EDTA tubes containing aprotinin in order to inhibit proteinase activity. Samples were centrifuged for $15 \mathrm{~min}$ at $1000 \times g$ at $4^{\circ} \mathrm{C}$ within 30 min of collection. Samples were stored at $-80^{\circ} \mathrm{C}$ until analysis.

Plasma ADAMTS-7 and BNP levels were measured by ELISA (ADAMTS-7 ELISA kit; WUHAN USCN SCIENCES CO., LTD., China; sE91974Ra; Rat BNP ELISA kit; Cusabio; CSB-E07972r), according to the manufacturers' instructions. The lower limits of detection for ADAMTS-7 and BNP were $0.078 \mathrm{ng} / \mathrm{mL}$ and $4.7 \mathrm{pg} / \mathrm{ml}$, respectively. The coefficient of variation was $<10 \%$.

\section{Echocardiography}

Echocardiography (Vivid E9, GE healthcare, Waukesha, WI, USA) was performed before rats were sacrificed by exsanguinations. A 7.5 MHz transducer was used at a depth of $3.0 \mathrm{~cm}$ and a sectorial angle of $60^{\circ}$. Under anesthesia by intraperitoneal injection of $40 \mathrm{mg} / \mathrm{kg}$ using pentobarbital sodium, rats were fixed on their backs with their fur shaved and skin cleaned. Animals with AMI were examined at day 28 to monitor the LV fractional shortening (LVFS) and LV ejection fraction (LVEF) using miniature probe M-mode ultrasound. The fractional shortening (FS) was acquired by measuring the LV end-diastolic diameter (LVDd) and LV end-systolic diameter (LVDs) of three cardiac cycles, using the formula LVFS (\%) = [(LVDd-LVDs)/ $\operatorname{LVDd}] \times 100 \%$, and $\operatorname{LVEF}(\%)=\left[\left(\mathrm{LVDd}^{3}-\mathrm{LVDS}^{3}\right) / \mathrm{LVDd}^{3}\right] \times 100 \%[14]$.

\section{Quantitative real-time RT-PCR}

Total RNA was extracted from the rat cardiac tissues using TRIzol (Life Technologies Co., Grand Island, NY, USA), according to the manufacturer's instructions. RNA concentration was determined using the absorbance at 260 and $280 \mathrm{~nm}$ (A260/280). Total RNA was reverse-transcribed into cDNAs using a PrimeScript $^{\mathrm{TM}}$ RT-PCR Kit (Takara Bio, Otsu, Japan). Primer sequences were: ADAMTS-7: forward: 5'-AAC CAG GAA CGC CTA CCT TT-3', reverse: 5'-CGG GGT CCT TGC TAC TGT TA-3' (product length: 159bp); and GAPDH: forward: 5'-CCC TCC ACC CAA GGA AAC T-3', reverse: 5'-GCC CTA CGC TGA ATG CTG A-3' (product length: 269bp). Real-time PCR amplification was performed using SYBR ${ }^{\circledR}$ Premix Ex Taq ${ }^{\text {TM }}$ (Perfect Real Time) (Takara Bio, Otsu, Japan). The reactions were carried out at $94^{\circ} \mathrm{C}$ for $3 \mathrm{~min}$, followed by 35 cycles at $94^{\circ} \mathrm{C}$ for $30 \mathrm{sec}, 54-62^{\circ} \mathrm{C}$ for $30 \mathrm{sec}$, and $72^{\circ} \mathrm{C}$ for $30 \mathrm{sec}$, and finally $72^{\circ} \mathrm{C}$ for $10 \mathrm{~min}$ (PRISM 7300, Applied Biosystems, Foster City, CA, USA). Expression of ADAMTS-7 was normalized to GAPDH. Expression was determined using the $2^{-\Delta \Delta C \mathrm{C}}$ method.

\section{Western blot}

Frozen tissues (100 mg) from each sample were homogenized for $10 \mathrm{~min}$ with a tissue protein lysis buffer (Beyotime Institute of Biotechnology, Haimen, China) using a homogenizer, chilled on ice for 30 min, and centrifuged at $10,000 \times \mathrm{g}$ for $5 \mathrm{~min}$ at $4^{\circ} \mathrm{C}$. The protein concentration was determined using a protein assay kit (BCA, Pierce Chemical, Dallas, TX, USA). The same amount of protein ( $50 \mu \mathrm{g}$ ) was separated by $8 \%$ SDS-PAGE and transferred to PVDF membranes (Jianglai Science and Technology Co., Ltd., Shanghai, China). The membrane was blocked with 5\% BSA for 1 hour at room temperature, followed by incubation with primary antibody against ADAMTS-7 (Abcam, Cambridge, UK, ab28557) and COMP (Abcam, Cambridge, UK, ab42225) overnight at $4^{\circ} \mathrm{C}$. Then, the corresponding HRP-conjugated secondary antibodies (ZSGB-Bio, Beijing, China) were incubated for 2 hour at room temperature. Proteins were detected using an enhanced chemiluminescence reagent (SuperSignal West Pico, Pierce Chemical, Dallas, TX, USA). Band intensity was quantified using the Odyssey infrared imaging system (LI-COR Biosciences, Lincoln, NE, USA). The 


\begin{tabular}{|c|c|c|}
\hline Cellular Physiology & Cell Physiol Biochem 2016;3 & 8:950-958 \\
\hline and Biochemistry & $\begin{array}{l}\text { DOI: } 10.1159 / 000443047 \\
\text { Published online: March 04, } 2016\end{array}$ & $\begin{array}{l}\text { O } 2016 \text { The Author(s). Published by S. Karger AG, Basel } \\
\text { wwww.karger.com/cpb }\end{array}$ \\
\hline
\end{tabular}

expression was normalized to that of translation initiation factor 5 (Santa Cruz Biotechnology, Santa Cruz, CA, USA) [15]. Quantitative analysis was performed using the Image J software (National Institutes of Health, Bethesda, MD, USA).

\section{Immunohistochemistry}

Consecutive frozen sections of heart were immunostained with anti-ADAMTS-7 antibody (Abcam, Cambridge, UK) to examine ADAMTS-7 expression 4 weeks after AMI using an immunohistochemistry kit (Zhongshan Jinqiao Biotechnology Co., Ltd., Beijing, China).

\section{Statistical Analysis}

Statistical analysis was performed using GraphPad Prism 4.0 (GraphPad Software Inc., San Diego, CA, USA). Continuous data are presented as mean \pm standard deviation (SD). Comparison between two groups was performed using independent samples $t$-tests (two-sided). Repeated measure ANOVA and the Tukey's post hoc test were used to analyze parameters' changes in time. Pearson Correlation was used to study the association between ADAMTS-7 levels and heart failure. $P$-values $<0.05$ were considered statistically significant.

\section{Results}

\section{AMI rat models}

Among the 40 rats in the AMI group, 10 died of ventricular fibrillation within 60 min after operation, five died of ventricular fibrillation during the operation, two died of heart failure, and two died of pulmonary edema. Among the 20 rats in the sham group, one died of infection and one died of pneumothorax.

\section{Cardiac function and structure}

Cardiac functional and structural parameters are presented in Table 1. Representative M-mode echocardiography images are presented in Fig. 1. Left atrial diameter (LAD), LVDd and LVDs were all larger in the AMI group at all time points after operation compared with baseline (before operation) and the sham group (all $P<0.05$ ). IVSTd and IVSTs were all smaller in the AMI group at all time points after operation compared with baseline and

Table 1. Cardiac functional and structural parameters using echocardiography in AMI rat models. LAD: feft atrial diameter; LVDd: left ventricular end-diastolic diameter; LVDs: left ventricular end-systolic diameter; IVSTs: end-systolic interventricular septal thickness; IVSTd: end-diastolic interventricular septal thickness; LVPWTs: left ventricular end-systolic diameter posterior wall thickness; LVPWTd: left ventricular end-diastolic diameter posterior wall thickness; LVEF: left ventricular ejection fraction; LVFS: left ventricular short-axis fractional shortening. Data are shown as mean \pm standard deviation (SD). ${ }^{*} P<0.001$ vs. sham; \# $P<0.05$ vs. before operation, ${ }^{\Delta} P<0.05$ vs. 7 days after operation; ${ }^{\wedge} P<0.05$ vs. 14 days after operation; ${ }^{\&} P<$ 0.05 vs. 28 days after operation

\begin{tabular}{|c|c|c|c|c|c|c|c|c|c|c|}
\hline \multirow[t]{2}{*}{ Parameter } & \multicolumn{2}{|c|}{ Before operation } & \multicolumn{8}{|c|}{ Post-operation } \\
\hline & $\begin{array}{l}\text { AMI } \\
(n=40)\end{array}$ & $\begin{array}{l}\text { Sham } \\
(n=20)\end{array}$ & $\begin{array}{l}\text { AMI }(\mathrm{n}=23) \\
(7 \text { days })\end{array}$ & $\begin{array}{l}\text { Sham } \\
(\mathrm{n}=18) \\
(7 \text { days })\end{array}$ & $\begin{array}{l}\text { AMI }(\mathrm{n}=22) \\
(14 \text { days })\end{array}$ & $\begin{array}{l}\text { Sham } \\
(\mathrm{n}=18) \\
(14 \text { days })\end{array}$ & $\begin{array}{l}\text { AMI }(\mathrm{n}=21) \\
(28 \text { days })\end{array}$ & $\begin{array}{l}\text { Sham }(n=18)(28 \\
\text { days })\end{array}$ & $\begin{array}{l}\text { AMI }(n=21)(42 \\
\text { days })\end{array}$ & $\begin{array}{l}\text { Sham }(n=18)(42 \\
\text { days })\end{array}$ \\
\hline$\overline{\mathrm{LAD}(\mathrm{mm})}$ & $3.28 \pm 0.16$ & $3.27 \pm 0.24$ & $4.28 \pm 0.34^{* \#}$ & $3.33 \pm 0.19$ & $4.28 \pm 0.29^{\prime} \#$ & $3.32 \pm 0.17$ & $4.32 \pm 0.14^{* \#}$ & $3.31 \pm 0.21$ & $4.30 \pm 0.22^{* \#}$ & $3.33 \pm 0.24$ \\
\hline LVDd (mm) & $5.68 \pm 0.59$ & $5.69 \pm 0.73$ & $8.88 \pm 0.72^{*} \#$ & $5.74 \pm 0.63$ & $9.11 \pm 0.42^{\prime \#}$ & $5.70 \pm 0.88$ & $9.81 \pm 0.57^{* \# \Delta}$ & $5.79 \pm 0.74$ & $9.82 \pm 0.55^{\circ * \Delta}$ & $5.76 \pm 0.62$ \\
\hline LVDs (mm) & $4.31 \pm 0.67$ & $4.29 \pm 0.66$ & $8.64 \pm 0.35^{* \#}$ & $4.33 \pm 0.63$ & $8.99 \pm 0.46^{*}$ & $4.29 \pm 0.77$ & $8.91 \pm 0.71^{* \#}$ & $4.22 \pm 0.63$ & $8.84 \pm 0.69^{*} \#$ & $4.26 \pm 0.83$ \\
\hline IVSTd (mm) & $1.12 \pm 0.14$ & $1.16 \pm 0.23$ & $0.61 \pm 0.16^{* \#}$ & $1.17 \pm 0.17$ & $0.68 \pm 0.26^{*} \#$ & $1.22 \pm 0.13$ & $0.66 \pm 0.14^{* \#}$ & $1.19 \pm 0.19$ & $0.65 \pm 0.85^{* \#}$ & $1.20 \pm 0.12$ \\
\hline IVSTs (mm) & $1.43 \pm 0.16$ & $1.35 \pm 0.23$ & $0.81 \pm 0.23^{x \#}$ & $1.33 \pm 0.18$ & $0.91 \pm 0.22^{\prime \#}$ & $1.34 \pm 0.20$ & $0.9 \pm 0.15^{x}$ & $1.36 \pm 0.21$ & $0.93 \pm 0.24 \# \Delta$ & $1.37 \pm 0.24$ \\
\hline $\begin{array}{l}\text { LVPWTd } \\
(\mathrm{mm})\end{array}$ & $2.33 \pm 0.35$ & $2.26 \pm 0.44$ & $2.23 \pm 0.33$ & $2.21 \pm 0.37$ & $2.01 \pm 0.12$ & $2.20 \pm 0.41$ & $2.03 \pm 0.32$ & $2.23 \pm 0.33$ & $2.00 \pm 0.52$ & $2.23 \pm 0.26$ \\
\hline $\begin{array}{l}\text { LVPWTs } \\
(\mathrm{mm})\end{array}$ & $2.67 \pm 0.46$ & $2.69 \pm 0.65$ & $2.63 \pm 0.27$ & $2.67 \pm 0.33$ & $2.66 \pm 0.33$ & $2.65 \pm 0.44$ & $2.60 \pm 0.30$ & $2.67 \pm 0.34$ & $2.68 \pm 0.28$ & $2.67 \pm 0.56$ \\
\hline LVFS (\%) & $26.70 \pm 5.96$ & $28.15 \pm 6.06$ & $8.82 \pm 2.99^{*} \#$ & $29.2 \pm 6.66$ & $9.34 \pm 1.57^{+\#}$ & $28.23 \pm 6.35$ & $9.10 \pm 2.62^{+\#}$ & $28.20 \pm 6.16$ & $11.10 \pm 4.67^{* \# \Delta}$ & $27.6 \pm 6.09$ \\
\hline $\operatorname{LVEF}(\%)$ & $62.66 \pm 8.49$ & $61.63 \pm 9.11$ & $18.67 \pm 7.58^{* \#}$ & $60.92 \pm 8.89$ & $23.76 \pm 7.65^{\sharp \#}$ & $61.21 \pm 9.11$ & $24.77 \pm 6.44^{* \#}$ & $60.61 \pm 9.01$ & $34.65 \pm 8.54^{* \# \Delta}$ & $61.52 \pm 8.89$ \\
\hline $\mathrm{BNP}(\mathrm{pg} / \mathrm{ml})$ & $0.65 \pm 0.12$ & $0.90 \pm 0.25$ & $5.83 \pm 1.23^{* \#}$ & $0.88 \pm 0.24$ & $4.05 \pm 0.78^{* \#}$ & $1.37 \pm 0.44$ & $3.65 \pm 0.32^{* \pm \Delta}$ & $0.90 \pm 0.21$ & $2.02 \pm 0.69 \# \Delta$ & $1.20 \pm 0.32$ \\
\hline
\end{tabular}




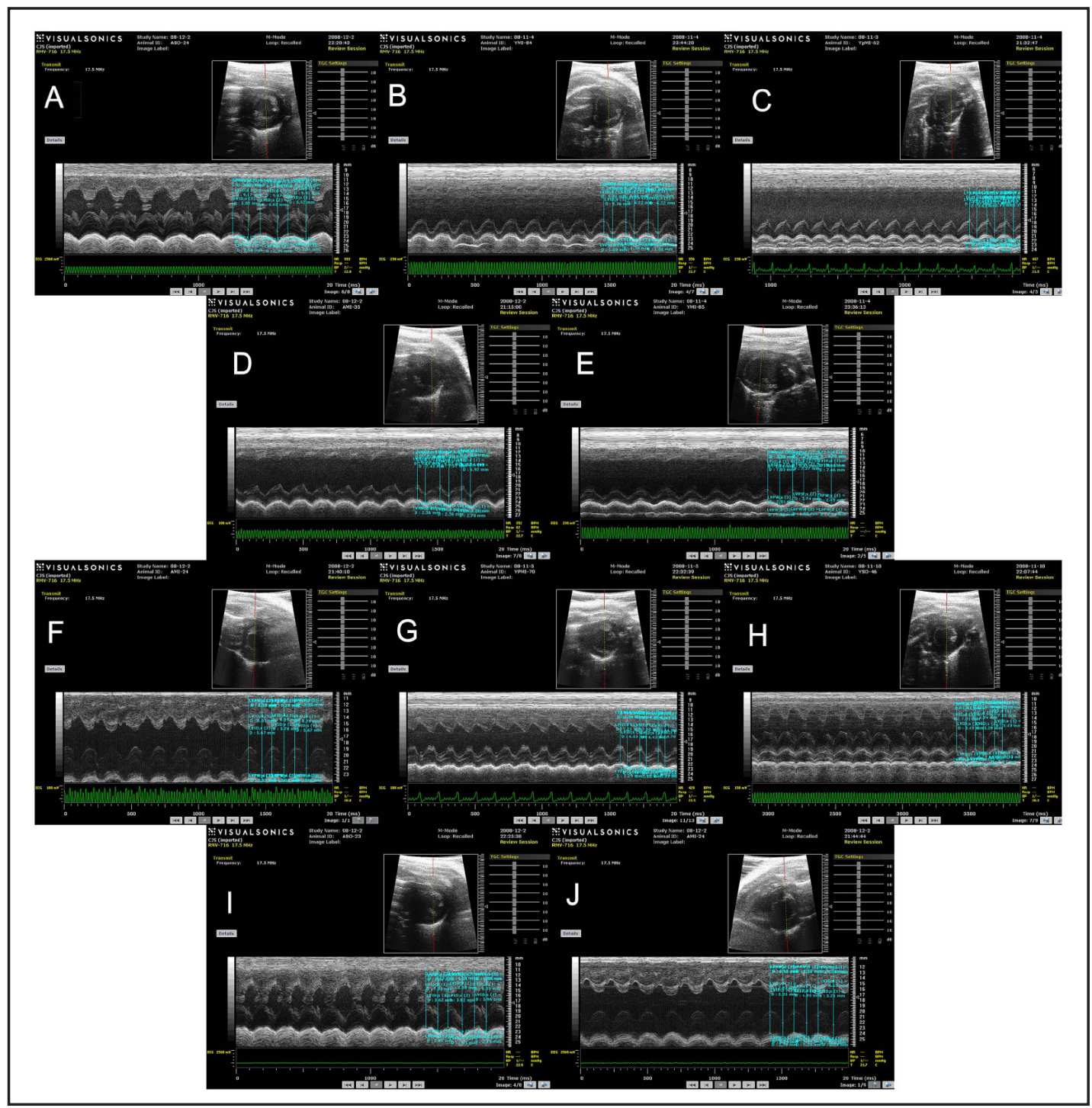

Fig. 1. Changes in M-mode echocardiography in the AMI group before operation (A) and 7 (B), 14 (C), 28 (D), and 42 (E) days after operation; and in the sham group before operation (F) and 7 (G), 14 (H), 28 (I), and 42 (J) days after operation.

Table 2. Changes in plasma ADAMTS-7 with time after AMI. Data are shown as mean \pm SD. ${ }^{*} P<0.001 v s$. sham; ${ }^{\#} P<0.05$ vs. before operation, ${ }^{\Delta} P<0.05$ vs. 7 days after operation; ${ }^{\Delta} P<0.05$ vs. 14 days after operation; ${ }^{\&} P<0.05$ vs. 28 days after operation

\begin{tabular}{|c|c|c|c|c|c|}
\hline \multirow[t]{2}{*}{ Group } & \multirow[t]{2}{*}{ Before operation $(\mathrm{ng} / \mathrm{mL})$} & \multicolumn{4}{|c|}{ Post-operation (ng/mL) } \\
\hline & & 7 days & 14 days & 28 days & 42 days \\
\hline Sham & $3.52 \pm 1.36(n=20)$ & $4.22 \pm 1.73(\mathrm{n}=18)$ & $3.64 \pm 1.55(n=18)$ & $3.39 \pm 1.27(\mathrm{n}=18)$ & $2.93 \pm 0.99(n=18)$ \\
\hline AMI & $3.49 \pm 1.61(n=40)$ & $8.86 \pm 3.74^{* \#}(n=23)$ & $10.42 \pm 5.35^{* \#}(n=22)$ & $13.24 \pm 6.26^{* \# \Delta}(\mathrm{n}=21)$ & $11.22 \pm 5.86^{*} \# \Delta \&(n=21)$ \\
\hline
\end{tabular}

the sham group (all $P<0.05$ ). LVFS and LVEF were all lower in the AMI group at all time points after operation compared with baseline and the sham group (all $P<0.05$ ). BNP levels were higher in the AMI group compared with baseline and the sham operated group at all time points (all $P<0.05$ ). In the AMI group, BNP levels peaked at 7 days, and then gradually decreased.

\section{KARGER}


Fig. 2. ADAMTS-7 mRNA expression, and ADAMTS-7 and COMP protein expressions in the infarction zone 28 days after AMI. (A) mRNA expression was determined by real-time RT-PCR, GAPDH was used as control. (B) Protein expression was determined by western blot. eIF-5 was used as control. Data are shown as mean \pm standard deviation (SD) ( $\mathrm{n}=6$ each group). ${ }^{*} P<0.05$ vs. the sham group.

Table 3. Association between ADAMTS-7 levels and cardiac functional parameters 28 days after AMI in rats

\begin{tabular}{lll}
\hline & \multicolumn{2}{l}{ ADAMTS-7 levels } \\
& $\mathrm{r}$ & $P$ \\
\hline LAD (mm) & 0.236 & 0.102 \\
LVDd (mm) & 0.695 & 0.041 \\
LVDs (mm) & 0.71 & 0.039 \\
IVSTd (mm) & 0.121 & 0.224 \\
IVSTs (mm) & 0.214 & 0.547 \\
LVPWTd (mm) & 0.013 & 0.687 \\
\hline
\end{tabular}

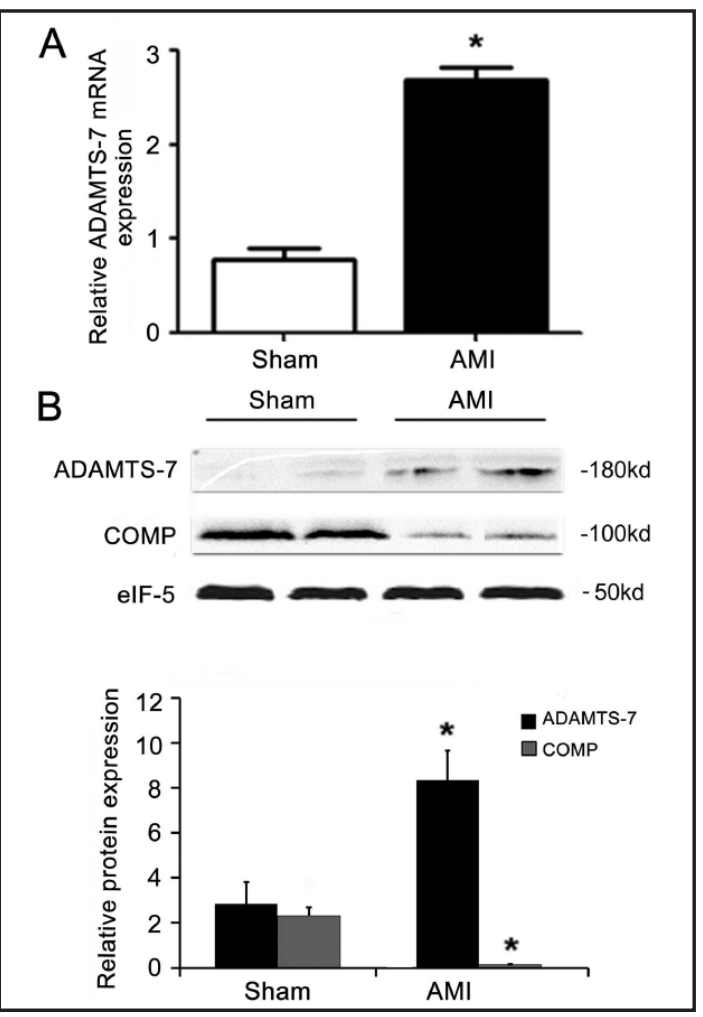

Fig. 3. ADAMTS-7 protein expression in rat hearts 28 days after AMI by immunohistochemistry (Magnification: $\times 100$ ).

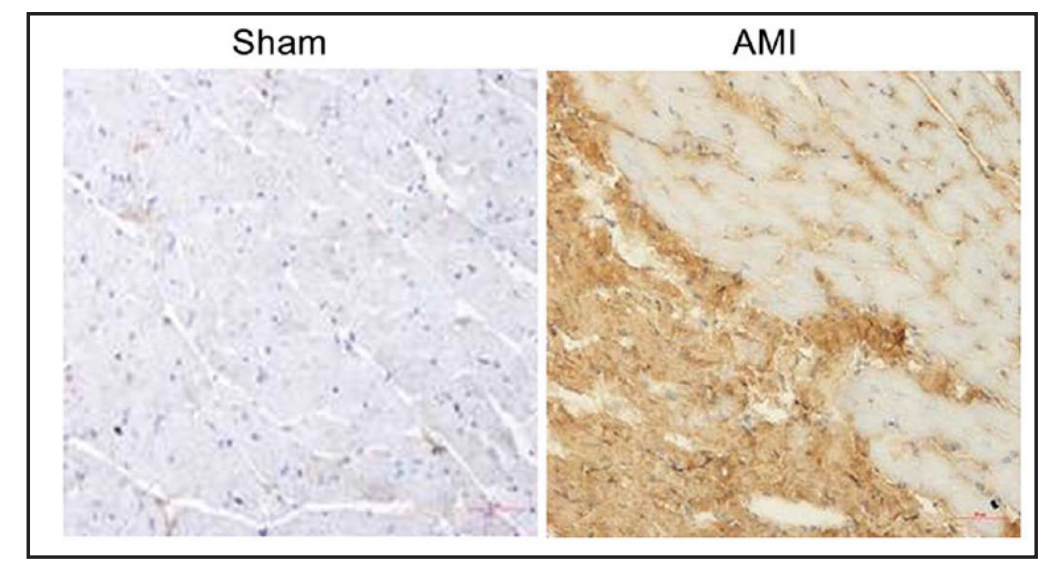

ADAMTS-7

Plasma ADAMTS-7 levels increased after AMI, and peaked 28 days after AMI, being higher than those in the sham group $(13.24 \pm 6.26 v s .3 .39 \pm 1.27 \mathrm{ng} / \mathrm{ml}, P<0.05)$ (Table 2). Western blot, real-time RT-PCR, and immunohistochemistry all revealed higher ADAMTS-7 expression in the infarction zone on day 28 (Fig. 2 and 3). As shown in Fig. 2B, western blot showed that COMP was present in normal myocardium and was degraded 4 weeks after AMI. mRNA levels of ADAMTS-7 in ischemic myocardium was upregulated by 3.5 folds compared with sham-operated heart (Fig. 2A).

Associations between ADAMTS-7 levels and heart failure parameters

Correlations between ADAMTS-7 levels and cardiac functional and structural parameters are shown in Table 3. Plasma ADAMTS-7 levels were positively correlated with BNP ( $\mathrm{r}=0.642, P=0.025)$, LVDd $(\mathrm{r}=0.695, P=0.041)$, LVDs $(\mathrm{r}=0.710, P=0.039)$, LVEF $(\mathrm{r}=$ $0.695, P=0.036)$, and LVFS $(r=0.721, P=0.024) 28$ days after AMI. 


\section{Discussion}

High levels of ADAMTS-7 are associated with AMI, but the involvement of ADAMTS-7 in ventricular remodeling is unknown. The aim of the present study was to examine the association between ADAMTS-7 expression and cardiac function in rats with AMI. Results showed that plasma ADAMTS-7 levels rose after AMI, and peaked on the $28^{\text {th }}$ day after AMI. Compared with the sham group, western blot, real-time RT-PCR, and immunohistochemistry revealed higher ADAMTS-7 expression in the infarction zone on day 28. Western blot showed the presence of COMP in normal myocardium and that it was degraded 28 days after AMI. Plasma ADAMTS-7 levels were positively correlated with BNP levels, LVDd, LVSd, LVEF, and LVFS. These results are consistent with our previous study about the expression of plasma ADAMTS-7 levels in patients with AMI and the relationship between plasma ADAMTS-7 levels and heart function [12].

The extracellular matrix (ECM) plays a major role in the maintenance of ventricular shape, size and function [5]. After AMI, the early degradation of ECM causes progressive dilation and thinning in the infarction zone, contributing to infarct expansion and leading to severe consequences including LV rupture, dilation, and dysfunction [16]. In addition, subsequent ECM disruption in the non-infarction zone leads to progressive global LV dilation over weeks [16].

ADAMTS-7 may be involved in cardiovascular diseases by degrading ECM [17]. Wang et al. [11] reported that ADAMTS-7 was a novel proteolytic culprit in vascular remodeling by mediating vascular smooth muscle cell migration and neointimal formation in ballooninjured rat arteries [18]. Another study reported that ADAMTS-7 was involved in neointimal thickening after cardiac injury [19]. Du et al. [20] reported that upregulation of ADAMTS-7 by miR-29 repression mediated vascular smooth muscle calcification. ADAMTS-7 is involved in the proliferative response to vascular injury in a way that is similar to the progressive phase of atherosclerosis [21]. A study showed an association between the ADAMTS-7 locus and angiographic coronary artery disease [19]. Huang et al. [22] reported the presence of COMP in cardiomyocytes, where it plays an essential role during the initiation and progression of dilated cardiomyopathy. In the present study, rat models of AMI revealed increased ADAMTS-7 expression and decreased COMP in the infarct area. Therefore, it may be hypothesized that ADAMTS-7 affects the ventricular remodeling process by degrading COMP after AMI.

Nevertheless, recent studies hint toward the mechanisms of ADAMTS-7 in cardiovascular diseases. Indeed, ADAMTS-7 has been shown to promote vascular remodeling via thrombospondin-1 [23]. ADAMTS-7 levels were correlated with inflammatory markers such as TNF- $\alpha$ and NF- $\mathrm{KB}$ in different inflammatory conditions and diseases [24-26], as well as in organ injury such as angiotensin-II renal injury [27]. Interestingly, recent findings suggested that activation of M1 but not M2 macrophages plays an important role in cardiac remodeling after myocardial infarction in rats [28]. In addition, peroxisome proliferator-activated receptor $\gamma$ (PPAR $\gamma$ ) activation was shown to inhibit cardiac remodeling via downregulation of Brg1 and transforming growth factor beta 1 (TGF- $\beta 1$ ) [29]. These findings further indicate that inflammation plays a role in atherosclerosis and AMI, and further study is necessary to understand the role of ADAMTS-7 in AMI in relation to inflammation.

The present study is not without limitations. The study was performed in animals, and results need to be confirmed in humans. The present study was not designed to provide any mechanistic insights into the roles of ADAMTS-7 after AMI. We should observe the ADAMTS-7 and COMP expression after specific knockdown of ADAMTS-7 by siRNA in vivo. In addition, the upstream effectors and mechanisms should also be explored.

\section{Conclusions}

In conclusion, elevated ADAMTS-7 levels may be involved in ventricular remodeling after AMI. 


\section{Cellular Physiology Cell Physiol Biochem 2016;38:950-958 \begin{tabular}{cl|l} 
DOI: 10.1159/000443047 & $\begin{array}{l}\text { O 2016 The Author(s). Published by S. Karger AG, Basel } \\
\text { www.karger.com/cpb }\end{array}$
\end{tabular} \\ Wu et al.: ADAMTS-7 and Cardiac Function in Rats with AMI}

\section{Acknowledgements}

This work was supported by grants from the National Natural Science Fund (30770865; 81170287), BEIJING LISHENG Cardiovascular Health Foundation (BYX-2013-019), the China-Japan Friendship Hospital Youth Science and Technology Excellence Project (2014-QNYC-B-13), and the China-Japan Friendship Hospital research topic within the hospital (2013-QN-26).

\section{Disclosure Statement}

The authors have no financial conflict of interest.

\section{References}

1 O'Gara PT, Kushner FG, Ascheim DD, Casey DE, Jr., Chung MK, de Lemos JA, Ettinger SM, Fang JC, Fesmire FM, Franklin BA, Granger CB, Krumholz HM, Linderbaum JA, Morrow DA, Newby LK, Ornato JP, Ou N, Radford MJ, Tamis-Holland JE, Tommaso CL, Tracy CM, Woo YJ, Zhao DX, Anderson JL, Jacobs AK, Halperin JL, Albert NM, Brindis RG, Creager MA, DeMets D, Guyton RA, Hochman JS, Kovacs RJ, Kushner FG, Ohman EM, Stevenson WG, Yancy CW, American College of Cardiology Foundation/American Heart Association Task Force on Practice G: 2013 ACCF/AHA guideline for the management of ST-elevation myocardial infarction: a report of the American College of Cardiology Foundation/American Heart Association Task Force on Practice Guidelines. Circulation 2013;127:e362-425.

2 Yeh RW, Sidney S, Chandra M, Sorel M, Selby JV, Go AS: Population trends in the incidence and outcomes of acute myocardial infarction. N Engl J Med 2010;362:2155-2165.

3 Fox KA, Steg PG, Eagle KA, Goodman SG, Anderson FA, Jr., Granger CB, Flather MD, Budaj A, Quill A, Gore JM, Investigators G: Decline in rates of death and heart failure in acute coronary syndromes, 1999-2006. JAMA 2007;297:1892-1900.

4 Puymirat E, Simon T, Steg PG, Schiele F, Gueret P, Blanchard D, Khalife K, Goldstein P, Cattan S, Vaur L, Cambou JP, Ferrieres J, Danchin N, Investigators UU, Investigators FM: Association of changes in clinical characteristics and management with improvement in survival among patients with ST-elevation myocardial infarction. JAMA 2012;308:998-1006.

5 Janicki JS, Brower GL: The role of myocardial fibrillar collagen in ventricular remodeling and function. J Card Fail 2002;8:S319-325.

6 Rathi S, Deedwania PC: The epidemiology and pathophysiology of heart failure. Med Clin North Am 2012;96:881-890.

7 Creemers EE, Cleutjens JP, Smits JF, Daemen MJ: Matrix metalloproteinase inhibition after myocardial infarction: a new approach to prevent heart failure? Circ Res 2001;89:201-210.

8 Fedak PW, Altamentova SM, Weisel RD, Nili N, Ohno N, Verma S, Lee TY, Kiani C, Mickle DA, Strauss BH, Li RK: Matrix remodeling in experimental and human heart failure: a possible regulatory role for TIMP-3. Am J Physiol Heart Circ Physiol 2003;284:H626-634.

9 Hughes BG, Schulz R: Targeting MMP-2 to treat ischemic heart injury. Basic Res Cardiol 2014;109:424.

10 Tortorella MD, Malfait F, Barve RA, Shieh HS, Malfait AM: A review of the ADAMTS family, pharmaceutical targets of the future. Curr Pharm Des 2009;15:2359-2374.

11 Wang L, Wang X, Kong W: ADAMTS-7, a novel proteolytic culprit in vascular remodeling. Sheng Li Xue Bao 2010;62:285-294.

12 Wu W, Zhou Y, Li Y, Li J, Ke Y, Wang Y, Zheng J: Association between plasma ADAMTS-7 levels and ventricular remodeling in patients with acute myocardial infarction. Eur J Med Res 2015;20:27.

13 Zheng J, Chin A, Duignan I, Won KH, Hong MK, Edelberg JM: Growth factor-mediated reversal of senescent dysfunction of ischemia-induced cardioprotection. Am J Physiol Heart Circ Physiol 2006;290:H525-530. 


\section{Cellular Physiology Cell Physiol Biochem 2016;38:950-958

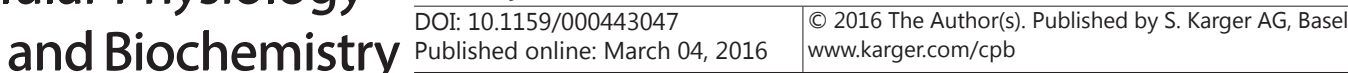 \\ Wu et al.: ADAMTS-7 and Cardiac Function in Rats with AMI}

14 Schiller NB, Shah PM, Crawford M, DeMaria A, Devereux R, Feigenbaum H, Gutgesell H, Reichek N, Sahn D, Schnittger I, et al.: Recommendations for quantitation of the left ventricle by two-dimensional echocardiography. American Society of Echocardiography Committee on Standards, Subcommittee on Quantitation of Two-Dimensional Echocardiograms. J Am Soc Echocardiogr 1989;2:358-367.

15 Dang Y, Kedersha N, Low WK, Romo D, Gorospe M, Kaufman R, Anderson P, Liu JO: Eukaryotic initiation factor 2alpha-independent pathway of stress granule induction by the natural product pateamine A. J Biol Chem 2006;281:32870-32878.

16 Chan W, Duffy SJ, White DA, Gao XM, Du XJ, Ellims AH, Dart AM, Taylor AJ: Acute left ventricular remodeling following myocardial infarction: coupling of regional healing with remote extracellular matrix expansion. JACC Cardiovasc Imaging 2012;5:884-893.

17 Porter S, Clark IM, Kevorkian L, Edwards DR: The ADAMTS metalloproteinases. Biochem J 2005;386:15-27.

18 Wang L, Zheng J, Bai X, Liu B, Liu CJ, Xu Q, Zhu Y, Wang N, Kong W, Wang X: ADAMTS-7 mediates vascular smooth muscle cell migration and neointima formation in balloon-injured rat arteries. Circ Res 2009;104:688-698.

19 Reilly MP, Li M, He J, Ferguson JF, Stylianou IM, Mehta NN, Burnett MS, Devaney JM, Knouff CW, Thompson JR, Horne BD, Stewart AF, Assimes TL, Wild PS, Allayee H, Nitschke PL, Patel RS, Myocardial Infarction Genetics C, Wellcome Trust Case Control C, Martinelli N, Girelli D, Quyyumi AA, Anderson JL, Erdmann J, Hall AS, Schunkert H, Quertermous T, Blankenberg S, Hazen SL, Roberts R, Kathiresan S, Samani NJ, Epstein SE, Rader DJ: Identification of ADAMTS7 as a novel locus for coronary atherosclerosis and association of $\mathrm{ABO}$ with myocardial infarction in the presence of coronary atherosclerosis: two genome-wide association studies. Lancet 2011;377:383-392.

20 Du Y, Gao C, Liu Z, Wang L, Liu B, He F, Zhang T, Wang Y, Wang X, Xu M, Luo GZ, Zhu Y, Xu Q, Wang X, Kong W: Upregulation of a disintegrin and metalloproteinase with thrombospondin motifs-7 by miR-29 repression mediates vascular smooth muscle calcification. Arterioscler Thromb Vasc Biol 2012;32:2580-2588.

21 Hansson GK: Inflammation, atherosclerosis, and coronary artery disease. N Engl J Med 2005;352:16851695.

22 Huang Y, Xia J, Zheng J, Geng B, Liu P, Yu F, Liu B, Zhang H, Xu M, Ye P, Zhu Y, Xu Q Wang X, Kong W: Deficiency of cartilage oligomeric matrix protein causes dilated cardiomyopathy. Basic Res Cardiol 2013;108:374.

23 Kessler T, Zhang L, Liu Z, Yin X, Huang Y, Wang Y, Fu Y, Mayr M, Ge Q, Xu Q Zhu Y, Wang X, Schmidt K, de Wit C, Erdmann J, Schunkert H, Aherrahrou Z, Kong W: ADAMTS-7 inhibits re-endothelialization of injured arteries and promotes vascular remodeling through cleavage of thrombospondin-1. Circulation 2015;131:1191-1201.

24 Li JK, Cheng L, Zhao YP, Guo YJ, Liu Y, Zhang W, Wang SS, Zhang YQ, Pan X, Nie L: ADAMTS-7 exhibits elevated expression in cartilage of osteonecrosis of femoral head and has a positive correlation with TNFalpha and NF- kappa B P65. Mediators Inflamm 2015;2015:196702.

25 Buckland J: Osteoarthritis: positive feedback between ADAMTS-7 and TNF in OA. Nat Rev Rheumatol 2013;9:566.

26 Lai Y, Bai X, Zhao Y, Tian Q, Liu B, Lin EA, Chen Y, Lee B, Appleton CT, Beier F, Yu XP, Liu CJ: ADAMTS-7 forms a positive feedback loop with TNF-alpha in the pathogenesis of osteoarthritis. Ann Rheum Dis 2014;73:1575-1584.

27 Gao YX, Yu CA, Lu JH, Gao HM, Li G, Kong W, Zheng J: ADAMTS-7 expression increases in the early stage of angiotensin II-induced renal injury in elderly mice. Kidney Blood Press Res 2013;38:121-131.

28 Liu W, Zhang X, Zhao M, Zhang X, Chi J, Liu Y, Lin F, Fu Y, Ma D, Yin X: Activation in M1 but not M2 Macrophages Contributes to Cardiac Remodeling after Myocardial Infarction in Rats: a Critical Role of the Calcium Sensing Receptor/NRLP3 Inflammasome. Cell Physiol Biochem 2015;35:2483-2500.

29 Qi HP, Wang Y, Zhang QH, Guo J, Li L, Cao YG, Li SZ, Li XL, Shi MM, Xu W, Li BY, Sun HL: Activation of peroxisome proliferator-activated receptor $\gamma$ (PPAR $\gamma$ ) through NF- $\kappa \mathrm{B} / \mathrm{Brg} 1$ and TGF- $\beta 1$ pathways attenuates cardiac remodeling in pressure-overloaded rat hearts. Cell Physiol Biochem 2015;35:899-912. 